\title{
Mapeamento de locos de características quantitativas nos cromossomos 5, 7 e 8 de suínos $^{1}$
}

\section{Katiene Régia Silva Sousa ${ }^{2}$, Simone Eliza Facioni Guimarães ${ }^{2,3}$, Miguel Inácio da Silva Filho $^{2}$, Marcos Soares Lopes ${ }^{2}$, Ana Paula Gomes Pinto ${ }^{2}$, Lucas Lima Verardo ${ }^{5}$, José Braccini Neto ${ }^{4}$, Paulo Sávio Lopes ${ }^{2,3}$}

\author{
${ }^{1}$ Fonte de financiamento: CNPq, CAPES e FAPEMIG. \\ 2 Departamento de Zootecnia, Universidade Federal de Viçosa, Viçosa, Minas Gerais, CEP: 36570-000. \\ 3 Pesquisador INCT - Ciência Animal. \\ ${ }^{4}$ Departamento de Zootecnia, Universidade Federal do Rio Grande do Sul, Porto Alegre, Rio Grande do Sul, CEP: $91540-000$. \\ ${ }^{5}$ Departamento de Genética e Melhoramento, Universidade Federal de Viçosa, Viçosa, Minas Gerais, CEP: 36570-000.
}

RESUMO - Objetivou-se mapear QTL nos cromossomos 5, 7 e 8 e associá-los a características de carcaça, cortes de carcaça, qualidade de carne, desempenho e órgãos internos de suínos. Uma progênie F2 de 614 animais foi produzida do cruzamento de dois varrões da raça naturalizada brasileira Piau e 18 fêmeas comerciais (Landrace $\times$ Large White $\times$ Pietrain). A população foi genotipada para 14 marcadores microssatélites cobrindo os cromossomos 5 , 7 e 8 . Em seguida, foi construído o mapa de ligação para cada cromossomo. As análises de associação foram feitas usando o mapeamento de intervalo por regressão para detecção de QTL. Para características de carcaça e cortes de carcaça, foram mapeados 20 QTL nos três cromossomos, enquanto, para características de qualidade de carne, foram encontrados apenas três QTL nos cromossomos 7 e 8. Entre eles, QTL significativos a 5\% no genoma foram encontrados para menor espessura de toucinho na região acima da última vértebra lombar, na linha dorsolombar no cromossomo 5; e para comprimento total do intestino delgado, peso da banha-rama e luminosidade no cromossomo 8. Para comprimento de carcaça pelo método brasileiro e comprimento de carcaça pelo método americano, QTL significativos a $1 \%$ no genoma foram encontrados no cromossomo 7 . Os resultados encontrados facilitarão estudos futuros, como o mapeamento fino e a identificação de genes que controlam a composição corporal e a qualidade de carne e que poderão ser incorporados em programas de seleção assistida por marcadores para acelerar o melhoramento genético de populações de suínos, além de ajudar no melhor entendimento da fisiologia das características de produção de suínos.

Palavras-chave: detecção de QTL, marcadores microssatélites, produção de suínos

\section{Mapping of quantitative trait loci mapping in chromosomes 5, 7 and 8 of swines}

\footnotetext{
ABSTRACT - The aim of this experiment was to map QTL in chromosomes 5, 7 and 8 and to associate them to carcass traits, carcass cuts, meat quality, performance and internal organs of swines. An F2 offspring with 614 animals was produced from the matting of two Brazilian naturalized Piau boars with 18 commercial females (Landrace $\times$ Large White $\times$ Pietrain). The population was genotyped for 14 microsatellite markers covering chromosomes 5,7 and 8 . After that, it was built the linkage map for each chromosome. Analysis of association were done using interval mapping by regression for QTL detection. For carcass and cuts of carcass traits, 20 QTL were mapped in the three chromosomes, whereas for traits of meat quality, only three QTL were found on chromosomes 7 and 8. Among them, significant QTL at 5\% in the genome were found for midline lower backfat thickness above the last lumbar vertebrae on chromosome 5; and for total length of small intestine, abdominal fat weight and brightness on chromosome 8. For carcass length by the Brazilian method and carcass length by the American method, it was found significant QTL at 1\% in the genome on chromosome 7 . The results found in this work will facilitate future researches as fine mapping and identification of genes that control body composition and meat quality and that will be able to be incorporated in marker-assisted selection programs to accelerate genetic improvement in swine populations, in addition to help a better understanding of the physiology of traits in swine production.
}

Key Words: microsatellite markers, QTL detection, swine production

Recebido em 13/4/2009 e aprovado em 15/12/2009

Correspondências devem ser enviadas para: sfacioni@ufv.br 


\section{Introdução}

O melhoramento da eficiência da produção e a melhoria da qualidade dos produtos são as maiores preocupações para os produtores de animais. A seleção dos melhores animais reprodutores é essencial para atingir essa meta e maiores informações sobre os futuros pais levam às melhores decisões (Edwards et al., 2008). Avanços na tecnologia genética, por meio da Seleção Assistida por Marcadores (MAS), permitem selecionar os animais que estão associados com os alelos favoráveis de QTL (Locos de Características Quantitativas, do inglês Quantitative Trait Loci), o que torna esta ferramenta interessante, uma vez que se podem selecionar os reprodutores por meio do genótipo do marcador (Haley \& Visscher, 1998), aumentando a eficiência no melhoramento animal, especialmente no caso de características de baixa herdabilidade ou aquelas que só podem ser mensuradas após o abate (Silva et al., 2003).

Para identificar essas regiões que controlam fenótipos de importância econômica em animais de produção, os marcadores moleculares microssatélites podem ser usados e a criação de populações experimentais tem sido utilizada para identificá-las (De Koning et al., 1999). Objetivou-se com este trabalho identificar QTL localizados nos cromossomos 5, 7 e 8 associados com características de carcaça, corte de carcaça, órgãos internos, vísceras, qualidade de carne e desempenho em uma população F2 de suínos.

\section{Material e Métodos}

A formação da população e a coleta dos dados fenotípicos foram realizadas na Granja de Melhoramento de Suínos do Departamento de Zootecnia da Universidade Federal de Viçosa, no período de novembro de 1998 a julho de 2001. Foi construída uma população F2 proveniente do cruzamento de dois varrões da raça naturalizada Brasileira Piau com 18 fêmeas originadas de linhagem desenvolvida na UFV pelo acasalamento de animais da linhagem comercial (Landrace $\times$ Large White $\times$ Pietrain) selecionados para desempenho.

Os machos da geração F2 foram castrados com 10 dias e todos os leitões foram desmamados aos 21 dias de idade; e, dos 77 aos 105 dias de idade, os animais foram submetidos ao teste de conversão alimentar individual. O abate dos animais, após a insensibilização elétrica, foi realizado quando o peso médio do animal atingia $65 \mathrm{~kg}$ de peso vivo. Antes do abate, os animais permaneceram em dieta hídrica por 18 horas. Maiores detalhes sobre a constituição desta população foram previamente publicados por Band et al. (2005a,b), Faria et al. (2006), Peixoto et al. (2006) e Silva et al. (2009).

Foram mensuradas na geração F2 as características: a) de desempenho: número de tetas; peso ao nascer; peso aos 21, 42, 63, 77 e 105 dias de idade, respectivamente; peso ao abate; ganho de peso médio diário dos 77 aos 105 dias; consumo de ração dos 77 aos 105 dias; conversão alimentar dos 77 aos 105 dias; e idade ao abate; b) de carcaça, órgãos internos e vísceras: rendimento de carcaça com cabeça e pés; comprimento de carcaça pelo método brasileiro de classificação de carcaças; comprimento de carcaça pelo método americano; maior espessura de toucinho na região da copa; espessura de toucinho imediatamente após última costela; espessura de toucinho entre última e penúltima vértebra lombar; menor espessura de toucinho na região acima da última vértebra lombar; espessura de toucinho imediatamente após última costela, a $6,5 \mathrm{~cm}$ da linha dorsolombar; espessura do bacon; profundidade de lombo; área de olho-de-lombo; peso de pulmão; peso de coração; peso de fígado; peso de baço; peso de rim e comprimento total do intestino delgado; c) de cortes de carcaça: peso do pernil; peso do pernil sem pele e sem capa de gordura; peso total da copa; peso da copa sem pele e sem capa de gordura; peso da paleta; peso da paleta sem pele e sem capa de gordura; peso do carré; peso do lombo; peso do bacon; peso das costelas; peso da papada; peso do filezinho; peso da banha-rama; e d) de qualidade de carne: $\mathrm{pH} 45$ minutos pós-abate; $\mathrm{pH} 24$ horas pós-abate; porcentagem de gordura intramuscular; perda por gotejamento; perda por cozimento; perda total; força de cisalhamento; luminosidade; índice de vermelho; índice de amarelo; tonalidade de cor; índice de saturação. A descrição detalhada sobre a metodologia empregada na análise das características de qualidade de carne foi apresentada por Benevenuto Júnior (2001).

Para a extração de DNA, foram coletadas amostras de sangue de todos os animais parentais, F1 e F2, conforme descrito por Band et al. (2005a,b) e Faria et al. (2006). Foram testados 23 marcadores na geração parental, escolhidos de acordo com o mapa consenso conforme a sua posição e número de alelos, para escolher 14 marcadores que foram informativos, por meio do programa CERVUS (Marshall et al., 1998), ao ser verificada a heterozigosidade observada, a heterozigosidade esperada e o conteúdo de informação polimórfica para posterior genotipagem dos animais F1e F2. Os 14 marcadores foram distribuídos no cromossomo 5 (SJ024, SW1987 e SW378), nos cromossomos 7 (S0025, S0064, S0102, SW252, SW632 e S0212) e 8(SW2410, S0098, SW905, S0017 e SW1085). Os alelos foram escoreados com base no tamanho relativo do padrão de DNA conhecido, utilizando o programa GeneScan ${ }^{\circledR}$ (Applied Biosystems). 
Essas análises foram realizadas utilizando-se o sequenciador automático ABI PRISM310, no Laboratório de Biotecnologia Animal, do Departamento de Zootecnia da Universidade Federal de Viçosa.

O mapa de ligação para cada cromossomo dos animais F2 foi feito utilizando-se o programa CRIMAP versão 2.4 (Green et al., 1990) e, juntamente com os dados genotípicos e fenotípicos foram submetidos ao programa GridQTL (Seaton et al., 2006) (http://www.gridqtl.org.uk/), que utiliza o método de regressão por intervalo de mapeamento (Haley et al., 1994), para detecção de QTL.

No modelo estatístico, assume-se que o QTL é bialélico, com alelos alternativos fixados em cada raça parental (Haley et al., 1994). Considerou-se que o genótipo QQ para os animais da raça naturalizada Piau, com efeito a, qq para os animais comerciais com efeito -a, e Qq para os animais heterozigotos, com efeito d. A probabilidade de cada indivíduo F2 apresentar um dos três genótipos do QTL foi calculada condicionalmente aos marcadores, a intervalos de 1 cM ao longo do cromossomo. Essas probabilidades foram usadas para fazer regressão das características em função dos efeitos genéticos aditivos e de dominância do QTL em estudo para cada animal.

Os níveis de significância cromossômica $(\alpha=0,05$ e $\alpha=0,01$ ) foram determinados utilizando o programa GridQTL, com teste de 10.000 permutações (Churchill \& Doerge, 1994) para cada característica. O nível de significância genômico foi obtido utilizando a correção de Bonferroni, que consiste em determinar o valor do nível de significância no cromossomo que proporcionará o nível de significância conjunto desejado; ou seja, o nível de significância desejado que deverá ser proporcional à contribuição de cada cromossomo para o comprimento total do genoma autossômico, como sugerido por De Koning et al. (1999) e Tuiskula-Haavisto et al. (2002).

A probabilidade genômica foi calculada pela seguinte equação:

$P_{\text {(genômico) }}=1-\left(1-P_{(\text {cromossomo })}\right)^{1 / r}$, em que $r$ é a contribuição de um cromossomo, que é obtida dividindo-se o comprimento do cromossomo testado pelo comprimento do genoma autossômico. O intervalo de confiança a 95\% $\left(\mathrm{IC}_{95 \%}\right)$ para a localização do QTL foi obtido usando a aproximação do qui-quadrado $\left(\chi^{2}\right)$, conforme descrito por Pérez-Enciso et al. (2000).

O seguinte modelo estatístico foi adotado:

$\mathrm{y}_{\mathrm{ijkl}}=\mathrm{S}_{\mathrm{i}}+\mathrm{L}_{\mathrm{j}}+\mathrm{H}_{\mathrm{k}}+\left(\mathrm{C}_{\mathrm{ijkl}}-\overline{\mathrm{C}}\right) \mathrm{b}+\mathrm{c}_{\mathrm{a}} \mathrm{a}+\mathrm{c}_{\mathrm{d}} \mathrm{d}+\mathrm{e}_{\mathrm{ijkl}}$ em que: $\mathrm{y}_{\mathrm{ijkl}}=$ fenótipo; $\mathrm{S}_{\mathrm{i}}=$ efeito fixo do sexo $\mathrm{i}, \mathrm{i}=1$ (macho), 2 (fêmea); $\mathrm{L}_{\mathrm{j}}$ = efeito fixo do lote ou da época de parição $\mathrm{j}, \mathrm{j}=1,2,3,4,5 ; \mathrm{H}_{\mathrm{k}}=$ efeito fixo do genótipo do gene do Halotano k, k=1(NN), $2(\mathrm{Nn}) ;\left(\mathrm{C}_{\mathrm{ijkl}}-\overline{\mathrm{C}}\right) \mathrm{b}=$ ajustamento para as covariáveis; $\mathrm{c}_{\mathrm{a}}=\mathrm{P}(\mathrm{QQ} / \mathrm{Mi})-\mathrm{P}(\mathrm{qq} / \mathrm{Mi})$ e $c_{\mathrm{d}}=\mathrm{P}(\mathrm{Qq} / \mathrm{Mi})$. Os coeficientes $c_{a}$ e $c_{d}$ são as funções de probabilidades condicionais do QTL dado o genótipo do marcador.

O genótipo para o gene halotano foi incluído como efeito fixo, uma vez que Band et al. (2005a,b) observaram não apenas a presença da mutação $\mathrm{Hal}_{1843}$ nesta população, mas também seus efeitos $(\mathrm{P}<0,05)$ sobre as características de desempenho, carcaça e qualidade de carne.

A fração aditiva da variância fenotípica $\left(\mathrm{h}^{2}{ }_{\mathrm{Q}}\right)$ observada na geração F2, explicada por um QTL, foi determinada de acordo com Pérez-Enciso et al. (2000), assumindo que alelos alternativos estejam fixados em cada raça, sendo $\mathrm{h}^{2}{ }_{\mathrm{Q}}=\mathrm{a}^{2} / 2 \sigma^{2} \mathrm{Y}$, em que $\sigma^{2} \mathrm{Y}$ é a variância residual considerando os efeitos fixos e as covariáveis, exceto o QTL e “a” é o efeito aditivo, gerado pelo programa GridQTL.

Para características de desempenho, como covariáveis, foram utilizadas: o tamanho de leitegada ao nascimento para peso ao nascer; o tamanho de leitegada ao desmame para P21, P42, P63, P77, P105 e peso ao abate e o peso aos 77 dias para consumo de ração, ganho de peso diário e conversão alimentar. Para as características de carcaça, o peso da carcaça ao abate foi considerado como covariável; o peso dabanda direita resfriada para as características de corte de carcaça; e como covariável para qualidade de carne, a idade ao abate.

\section{Resultados e Discussão}

Todos os locos utilizados neste trabalho foram considerados eficientes nos estudos de detecção de QTL de acordo com a heterozigosidade e o conteúdo de informação polimórfica observados (Tabela 1). Os locos SJ024, SW1987, S0064, S0102, SW252, SW632, S0212, S0098 e S0017 são altamente polimórficos; pois, segundo Ott(1992), um marcador é altamente polimórfico quando apresenta heterozigosidade observada superior a 0,70. Conforme Botstein et al. (1980), os locos que apresentaram valores superiores a 0,5 para o conteúdo de informação polimórfica são considerados muito informativos (SJ024, SW1987, S0064, S0102, SW252, SW632, S0212, SW2410, S0098 e S00170) e os locos SW378, S0025, SW905 e SW1085 foram moderamente informativos, pois apresentaram valores entre 0,25 e 0,50 (Tabela 1 ).

Os comprimentos dos mapas (média entre sexos), calculados de acordo com as meioses materna e paterna, gerados para os cromossomos 5, 7 e 8 foram 146, 136 e 148 cM, porém diferiram daqueles obtidos por Rohrer et al. (1996), Paszek et al. (1999), Marklund et al. (1996) e Archibald et al. (1995) em relação à posição dos marcadores 
Tabela 1 - Heterozigosidade esperada e observada, conteúdo de informação polimórfica e posição dos locos utilizados no mapeamento dos cromossomos 5, 7 e 8 de suínos

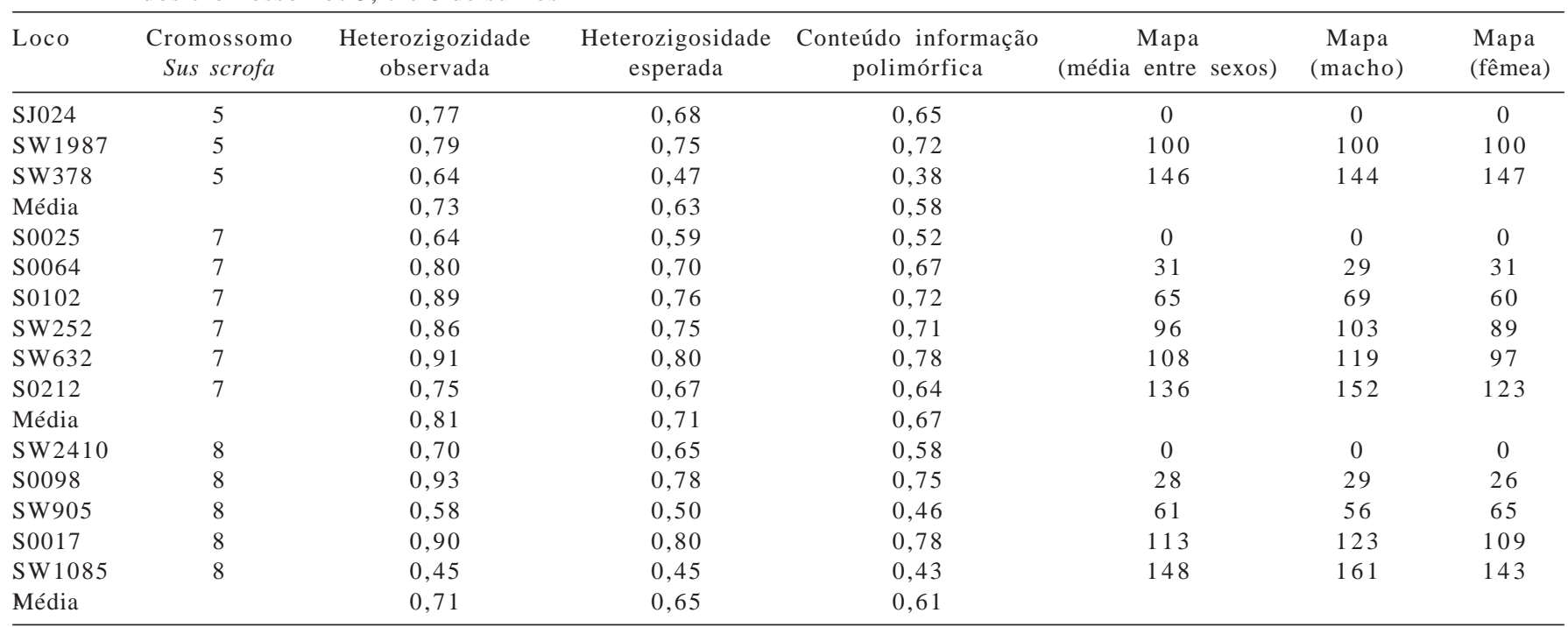

utilizados. Essas variações entre os mapas, segundo Geldermann et al. (2003), podem ser causadas devido às diferenças nas taxas de recombinação e às raças utilizadas por cada grupo de pesquisa, que são distintas. Não se espera que os mapas gerados em diferentes populações venham a apresentar exatamente o mesmo tamanho, pois, além de não utilizarem as mesmas populações, os conjuntos de marcadores são diferentes. Os mapas das fêmeas em relação aos cromossomos 7 e 8 apresentaram-se 1,24 e 1,13 vez maior que os dos machos, exceto o do cromossomo 5 , no qual o mapa dos machos foi 1,02 vez maior que o das fêmeas, o que pode ter acontecido pela baixa densidade de marcadores neste cromossomo (Tabela 1).

Para as características de carcaça, foi detectada região cromossômica significativa para comprimento de carcaça pelo método americano no cromossomo 5 (Tabela 2), que mostra ação gênica aditiva com influência dos alelos da linhagem comercial $(\mathrm{a}=-0,68 \pm 0,23)$. Esse QTL apresenta pico máximo na posição 107 cM. O QTL significativo para espessura de toucinho entre a última e a penúltima vértebra lombar detectado nesse mesmo cromossomo na posição 124 cM foi também encontrado por Malek et al. (2001), porém na posição 134,4 cM, em uma população oriunda do cruzamento de Berkshire e Yorkshire, e por Kim et al. (2005) na posição 127 cM ( IC $_{95 \%}$ de 125 a 130 cM) em uma população oriunda do intercruzamento de dois varrões Berkshire e nove matrizes Yorkshire. Próximo a essas regiões, encontra-se o gene candidato IGF-I (118,7 cM) que está associado ao crescimento e às características de carcaça em suínos.

Tabela 2 - Estatísticas F máximas (Fmax), com suas posições em cM, intervalo de confiança a 95\% (IC $95 \%$ ) e estimativas dos efeitos aditivos e de dominância para as características significativas no cromossomo 5

\begin{tabular}{|c|c|c|c|c|c|c|}
\hline Caracerística $^{1}$ & $\mathrm{~N}^{2}$ & Posição $\left(\mathrm{IC}_{95 \%}{ }^{3}\right)$ & $\mathrm{a} \pm \mathrm{EP}$ & $\mathrm{d} \pm \mathrm{EP}$ & $\mathrm{h}^{2} \mathrm{Q}(\%)$ & Fmax \\
\hline & & & Carcaça & & & \\
\hline MLC & 427 & $107(63-136)$ & $-0,68 \pm 0,23$ & $0,11 \pm 0,39$ & 3,47 & $4,91^{*}$ \\
\hline ETUC & 427 & $119(64-146)$ & $1,34 \pm 0,47$ & $-0,70 \pm 0,97$ & 4,85 & $5,23^{*}$ \\
\hline ETUL & 427 & $124(124-146)$ & $1,71 \pm 0,54$ & $1,46 \pm 1,05$ & 5,45 & $5,37 *$ \\
\hline ETL & 427 & $135(118-146)$ & $2,58 \pm 0,62$ & $1,66 \pm 1,36$ & 11,67 & $8,69 * * *$ \\
\hline ETO & 427 & $10(0-40)$ & $0,32 \pm 0,33$ & $2,49 \pm 0,74$ & 0,48 & $5,84 * *$ \\
\hline PB & 540 & $0(0-45)$ & $\begin{array}{c}\text { Corte de carcaça } \\
0,09 \pm 0,03\end{array}$ & $0,01 \pm 0,05$ & 3,90 & $5,41^{*}$ \\
\hline
\end{tabular}

${ }^{1}$ Características de carcaça: MLC - comprimento de carcaça pelo método americano (cm); MBCC - comprimento de carcaça pelo método brasileiro (cm); ETUC - espessura de toucinho imediatamente após a última costela, na linha dorsolombar (mm); ETUL - espessura de toucinho entre a última e a penúltima acima da última vértebra lombar, na linha dorsolombar $(\mathrm{mm})$, ETL - menor espessura de toucinho na região acima da última vértebra lombar, na linha dorsolombar; ETO - espessura de toucinho medida imediatamente após a última costela, a 6,5 cm da linha dorsolombar $(\mathrm{mm})$. Característica de corte de carcaça: PB - peso de bacon (kg).

2 Número de animais utilizados na análise,

${ }^{3}$ Intervalo com $95 \%$ confiança (cM); a - efeito aditivo, d - efeito de dominância, EP - erro-padrão; ${ }^{2}{ }_{\mathrm{Q}}$ - fração da variância fenotípica na $\mathrm{F}_{2}$ explicada pelo QTL em porcentagem.

* significativo a $5 \%$ no cromossomo.

** significativo a $1 \%$ no cromossomo.

*** significativo a $5 \%$ no genoma. 
Ainda para o SSC5, Rohrer \& Keele (1998) observaram QTL para menor espessura de toucinho na região acima da última vértebra lombar, na posição 57,9 cM, diferentemente do QTL obtido neste estudo, significativo a 5\% no genoma, encontrado na porção telomérica do cromossomo (135 cM, $\mathrm{IC}_{95 \%}$ de 118 a 146 cM). A significância no genoma é usada para detectar a presença de QTL dentro do genoma, controlando o erro do tipo I (falso-positivo) (Churchill \& Doerge, 1994). Essa região significativa apresenta estimativa do efeito genético aditivo indicando que os alelos da raça Piau influenciam aumentando em 2,58 mm em média por alelo a característica menor espessura de toucinho na região acima da última vértebra lombar. Um QTL para espessura de toucinho imediatamente após a última costela, a 6,5 cm da linha dorsolombar, constatado ainda neste cromossomo apresentou ação gênica aditiva de 0,32 $\pm 0,33$. Para as características de corte de carcaça, no cromossomo 5, foi detectado apenas um QTL para peso de bacon, que explicou 3,90\% da variância fenotípica com efeitos favoráveis dos alelos Piau, o que já era esperado por esta ser uma raça de alta deposição de gordura.

Apesar de a literatura consultada apresentar vários QTL para as características de qualidade da carne e desempenho no cromossomo 5, neste trabalho não foi detectado QTL significativo, o que pode indicar que não há segregação alélica nos genes deste cromossomo na população estudada.

No cromossomo 7, para características de carcaça, foram encontrados QTL para comprimento da carcaça pelo método brasileiro e pelo método americano na região centromérica (Figura 1; Tabela 3), ambos significativos a 1\% no genoma e apresentando ação gênica positiva de $1,14 \pm 0,27$ e 0,91 $\pm 0,21$, respectivamente; portanto, os alelos da raça Piau influenciam as características. O QTL para comprimento de carcaça pelo método americano também foi encontrado em outros estudos, porém em diversas regiões no cromossomo 7 por Nezer et al. (2002), Yue et al. (2003), Geldermann et al. (2003), Edwards et al. (2008) com pico em 99, 47, 65 e 59 cM, respectivamente.

Quanto ao QTL significativo para espessura de toucinho imediatamente após a última costela (Tabela 3) no cromossomo 7 encontrado neste estudo na região de 66 cM ( IC $_{95 \%}$ de 49 a 82 cM), também foi a mesma região reportada por Rohrer (2000) para mesma característica, que está associada com deposição de gordura. Entretanto, houve influência dos alelos da linhagem Comercial $(a=-1,18 \pm 0,35)$ sobre a característica em observação. Evidências de QTL em algumas características de carcaça também foram encontradas por Wang et al. (1998) no cromossomo 7. Esses autores ressaltaram que o QTL encontrado por eles relacionado com deposição de gordura está próximo ao loco do Fator de Necrose Tumoral $\alpha$ (TNF $\alpha$, entre os locos S0064 e S0102), indicando que o $\mathrm{TNF} \alpha$ ou outros genes estreitamente ligados, possam estar associados à deposição de gordura em suínos. Baskin \& Pomp (1998) sugerem que o TNF $\alpha$ possui função na deposição de gordura em humanos, assim como o gene Colipase, que também é encontrado nessa região e está relacionado com o metabolismo lipídico. Além desses, neste mesmo cromossomo, o SLA (Swine Leukocyte Antigens) também tem sido relacionado com

Tabela 3 - Estatísticas F máximas (Fmax), com suas posições (em cM), o intervalo de confiança a 95\% (IC $95 \%$ ) e estimativas dos efeitos aditivos e de dominância para as características significativas no cromossomo 7

\begin{tabular}{|c|c|c|c|c|c|c|}
\hline Caracerística $^{1}$ & № animais & Posição $\left(\mathrm{IC}_{95 \%}\right)$ & $\mathrm{a} \pm \mathrm{EP}$ & $\mathrm{d} \pm \mathrm{EP}$ & $\mathrm{h}^{2} \mathrm{Q}(\%)$ & Fmax \\
\hline & & & Carcaça & & & \\
\hline MBCC & 427 & $62(51-72)$ & $1,14 \pm 0,27$ & $-0,70 \pm 0,40$ & 6,31 & $10,7 * * * *$ \\
\hline MLC & 427 & $66(52-72)$ & $0,91 \pm 0,21$ & $-0,27 \pm 0,30$ & 6,15 & $10,2 * * * *$ \\
\hline ETUC & 427 & $66(49-82)$ & $-1,18 \pm 0,35$ & $0,12 \pm 0,50$ & 3,79 & $5,89 *$ \\
\hline PROLOM & 427 & $43(32-56)$ & $-1,06 \pm 0,48$ & $-2,38 \pm 0,85$ & 2,61 & $6,88 *$ \\
\hline \multirow[t]{2}{*}{ INTEST } & 427 & $64(44-80)$ & $0,46 \pm 0,14$ & $-0,09 \pm 0,20$ & 3,5 & $5,52 *$ \\
\hline & & & Cortes de carcaça & & & \\
\hline P P A & 540 & $78(52-87)$ & $0,11 \pm 0,03$ & $-0,06 \pm 0,06$ & 5,10 & $6,45^{*}$ \\
\hline PC & 540 & $66(59-80)$ & $-0,09 \pm 0,02$ & $-0,05 \pm 0,04$ & 4,16 & $6,94^{*}$ \\
\hline PBR & 540 & $60(45-75)$ & $-0,04 \pm 0,01$ & $0,01 \pm 0,02$ & 5,75 & $7,57 * *$ \\
\hline $\mathrm{L}$ & 452 & $96(85-97)$ & $\begin{array}{c}\text { Qualidade de carne } \\
0,03 \pm 0,15\end{array}$ & $-0,79 \pm 0,24$ & 0,01 & $5,57 *$ \\
\hline
\end{tabular}

${ }^{1}$ Características de carcaça: MBCC - comprimento de carcaça pelo método brasileiro (cm); MLC - comprimento de carcaça pelo método americano (cm); ETUC - espessura de toucinho imediatamente após a última costela, na linha dorsolombar (mm); PROLOM - diâmetro do músculo longissimus dorsi na região da última costela a 6,5 cm da linha dorsolombar, a partir de um corte transversal no carré; INTEST - comprimento total do intestino delgado (m). Características de corte de carcaça: PPA - peso total da paleta (kg); PC - peso total do carré (kg); PBR - peso de banha-rama (kg). Características de qualidade de carne: L - luminosidade.

IC -- intervalo com 95\% confiança (cM); a - efeito aditivo, d - efeito de dominância, EP - erro-padrão; ${ }^{2}{ }_{\mathrm{Q}}$ - fração da variância fenotípica na $\mathrm{F}_{2}$ explicada pelo QTL em porcentagem.

* significativo a $5 \%$ no cromossomo.

** significativo a $1 \%$ no cromossomo

**** significativo a $1 \%$ no genoma. 


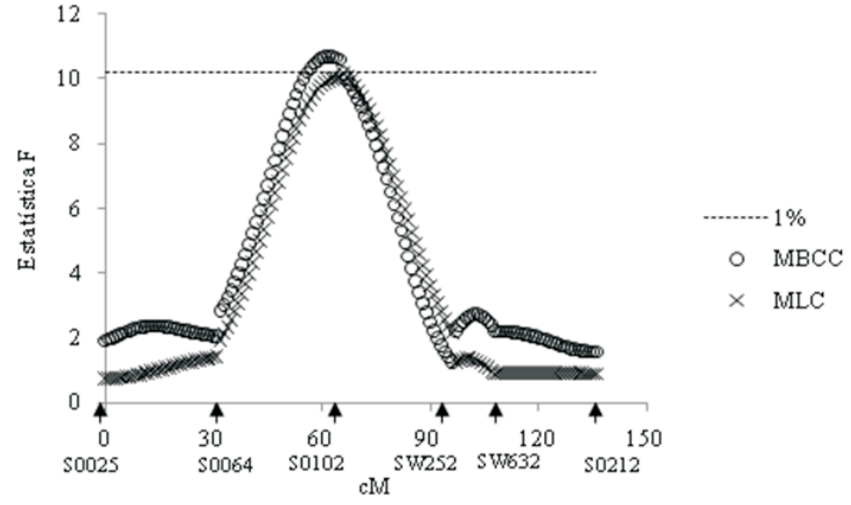

A linha horizontal indica o nível de significância de $1 \%$ no genoma (…).

Figura 1 - Valores da estatística F para análise de QTL no cromossomo 7 para comprimento de carcaça pelos métodos brasileiro (MBCC) e americano (MLC) de classificação de carcaças.

características de carcaça (Yue et al., 2003). Ainda foram encontrados QTL para profundidade do lombo, que também fora obtido por Wimmers et al. (2006), porém na região telomérica do cromossomo e para comprimento total do intestino delgado (Tabela 3), esse não encontrado na literatura consultada.

Observou-se, para características de corte de carcaça no cromossomo 7 , região significativa para peso da paleta ( $\mathrm{IC}_{95 \%}$ de 52 a $87 \mathrm{cM}$ ) com efeito genético aditivo de $0,11 \pm 0,03$ sobre a característica e com $5,10 \%$ da variação fenotípica explicada pelo QTL na população em estudo.
Milan et al. (2002) encontraram QTL com pico na região de 67 cM ( $\left(\mathrm{IC}_{95 \%}\right.$ de 61 a 82 cM) em uma população de Meishan e Large White, assim como Sanchez et al. (2006) encontraram QTL em um IC $_{95 \%}$ de 48 a 70 cM na mesma população. Também foi encontrado QTL para peso do carré neste cromossomo com influência dos alelos da linhagem Comercial, diminuindo o peso de carré em $0,09 \mathrm{~kg}$ a cada alelo adquirido da linhagem Comercial. Milan et al. (2002) e Sanchez et al. (2006) detectaram QTL para a mesma característica no IC $_{95 \%}$ de 87 a $111 \mathrm{cM}$ e 70 a $104 \mathrm{cM}$, respectivamente.

Um QTL foi detectado no cromossomo 7 para peso da banha-rama a 1\% de significância no cromossomo, o que explica 5,75\% da variação fenotípica na população F2, com efeito genético aditivo da linhagem comercial $(-0,04 \pm 0,01)$, influenciando a característica. Yue et al. (2003) evidenciaram QTL para peso da banha rama, no mesmo cromossomo, localizado na posição 82,5 cM e explicando 8,4\% da variância fenotípica na população F2 de Meishan e Pietrain e, encontraram também QTL para peso da banha rama no cruzamento divergente de porco selvagem e Pietrain que explicava, na posição 38,2 cM, 4,7\% da variação fenotípica nos animais $F_{2}$. De Koning et al. (1999) evidenciaram QTL para peso da banha rama com efeito de dominância posicionado a $75 \mathrm{cM}$.

Apenas um QTL foi encontrado para qualidade de carne no cromossomo 7 para luminosidade, apresentando influência dos alelos da raça Piau $(a=0,03 \pm 0,15)$ em um IC $_{95 \%}$ de 85 a 97 cM. Outros QTL para a mesma característica foram detectados por Malek et al. (2001), Ovilo et al. (2002) e Edwards et al. (2008).

Tabela 4 - Estatísticas F máximas (Fmax), com suas posições (em cM), intervalo de confiança a 95\% (IC ${ }_{95 \%}$ ) e estimativas dos efeitos aditivos e de dominância para as características significativas no cromossomo 8 de suínos

\begin{tabular}{|c|c|c|c|c|c|c|}
\hline Caracerística $^{1}$ & № animais & Posição $\left(\mathrm{IC}_{95 \%}{ }^{3}\right)$ & $\mathrm{a} \pm \mathrm{EP}$ & $d \pm E P$ & $\mathrm{~h}^{2}{ }_{\mathrm{Q}}(\%)$ & Fmax \\
\hline & & & Carcaça & & & \\
\hline ETL & 427 & $91(85-97)$ & $1,59 \pm 0,58$ & $2,13 \pm 1,19$ & 4,41 & $5,58^{*}$ \\
\hline ETO & 427 & $135(81-148)$ & $1,19 \pm 0,32$ & $0,26 \pm 0,64$ & 6,81 & $7,72 * *$ \\
\hline \multirow[t]{2}{*}{ INTEST } & 427 & $39(29-53)$ & $-0,60 \pm 0,15$ & $-0,74 \pm 0,28$ & 6,00 & $9,26 * * *$ \\
\hline & & & Cortes de carcaça & & & \\
\hline P P L & 539 & $137(117-49)$ & $-0,12 \pm 0,04$ & $-0,12 \pm 0,07$ & 4,69 & $7,56 * *$ \\
\hline PL & 540 & $133(114-149)$ & $-0,05 \pm 0,01$ & $-0,01 \pm 0,03$ & 6,42 & $7,28 * *$ \\
\hline \multirow[t]{2}{*}{ PBR } & 540 & $126(88-148)$ & $0,04 \pm 0,01$ & $0,05 \pm 0,02$ & 4,88 & $8,57 * * *$ \\
\hline & & & Qualidade de carne & & & \\
\hline Luminosidade & 452 & $106(87-120)$ & $-0,61 \pm 0,17$ & $-0,47 \pm 0,27$ & 5,21 & $8,10 * * *$ \\
\hline Índice de amarelo & 453 & $113(88-135)$ & $-0,12 \pm 0,04$ & $-0,07 \pm 0,06$ & 2,68 & $5,10 *$ \\
\hline
\end{tabular}

${ }^{1}$ Características de carcaça: ETL - menor espessura de toucinho na região acima da última vértebra lombar, na linha dorsolombar; ETO - espessura de toucinho medida imediatamente após a última costela, a $6,5 \mathrm{~cm}$ da linha dorsolombar (mm); INTEST - comprimento total do intestino delgado (m). Características de corte de carcaça: PPL - peso do pernil sem pele e sem capa de gordura (kg); PL - peso do lombo (kg); PBR - peso de banha-rama (kg). Características de qualidade de carne: L - luminosidade; B - índice de amarelo.

IC - intervalo com 95\% confiança (cM); a - efeito aditivo, d - efeito de dominância, EP - erro-padrão; ${ }^{2}{ }_{Q}$ - fração da variância fenotípica na $F_{2}$ explicada pelo QTL (\%).

* significativo a $5 \%$ no cromossomo.

** significativo a $1 \%$ no cromossomo.

*** significativo a $5 \%$ no genoma. 
No cromossomo 8, foi verificado QTL para menor espessura de toucinho na região da última vértebra lombar na porção 91 cM ( IC $_{95 \%}$ de 85 a 97 cM), explicando 4,41\% da variância fenotípica na população F2, com efeito genético aditivo de 1,59 $\pm 0,58$ sobre a característica (Tabela 4). Esse resultado também foi encontrado por Rohrer (2000), na mesma região, em uma população de Meishan e Composto Branco. Também foi constatado QTL para espessura de toucinho imediatamente após a última costela, a $6,5 \mathrm{~cm}$ da linha dorsolombar, com efeito genético aditivo de 1,19 \pm 0,32 influenciando essa característica. Esse padrão também era esperado, uma vez que a raça Piau é reconhecidamente grande depositora de gordura na carcaça. Bidanel et al. (2001) analisaram uma população F2 de Meishan e Large White e encontraram QTL para espessura de toucinho imediatamente após a última costela, a 6,5 cm da linha dorsolombar no $\mathrm{IC}_{95 \%}$ de 21 a $53 \mathrm{cM}$, diferentemente da posição encontrada neste estudo ( $\mathrm{IC}_{95 \%}$ de 81 a $148 \mathrm{cM}$ ). Um QTL detectado no cromossomo 8 foi significativo a 5\% no genoma para comprimento total do intestino em um IC $_{95 \%}$ de 29 a 53 cM e explica 6,0\% da variância fenotípica na população F2 (Tabela 4). QTL para comprimento de intestino foi também mencionado por Knott et al. (1998) ao estudarem o cruzamento de porcos selvagens europeu e Large White, com pico na região de $60 \mathrm{cM}$.

No cromossomo 8, foram encontrados QTL para peso do pernil sem pele e sem capa de gordura e peso do lombo, ambos influenciados pelos alelos da linhagem Comercial, pois apresentavam as estimativas dos efeitos genéticos aditivos negativos $(-0,12 \pm 0,04 \mathrm{e}-0,05 \pm 0,01)$, em um $\mathrm{IC}_{95 \%}$ de 117 a 149 cM e 114 a 149 cM, respectivamente (Figura 2).

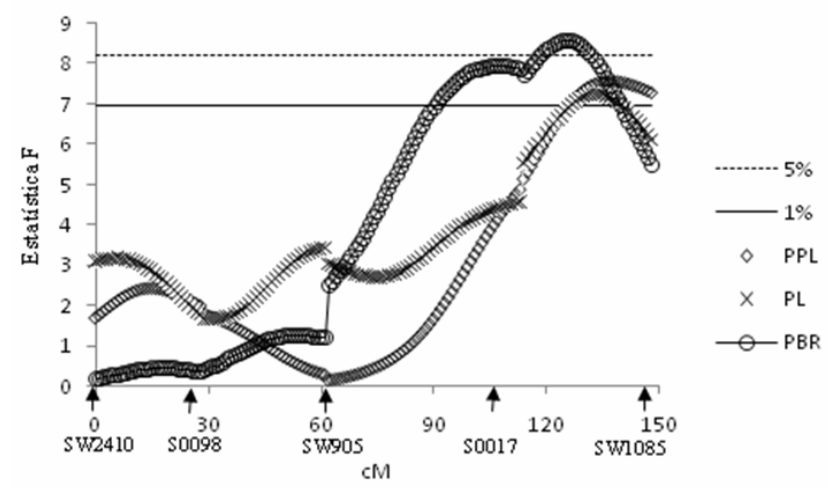

As linhas horizontais indicam os níveis de significância de 1\% no cromossomo (—) e $5 \%$ no genoma ( $\cdots)$.

Figura 2 - Valores da estatística F para análise de QTL no cromossomo 8 de suínos para as características de corte de carcaça PPL - peso do pernil sem pele e sem capa de gordura $(\mathrm{kg})(\diamond \diamond)$; PL - peso do lombo $\left({ }^{\mathrm{Xx}}\right)$ e PBR - peso de banha-rama (oo).

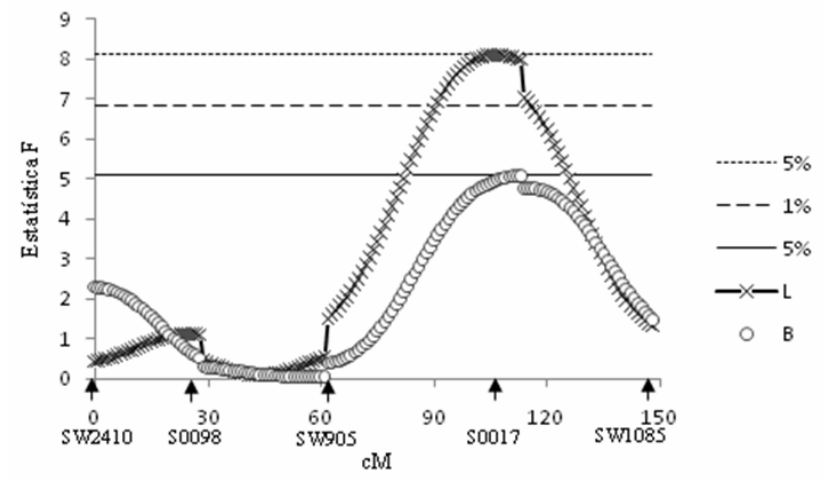

As linhas horizontais indicam os níveis de significância de 5\% no cromossomo (- -); $1 \%$ no cromossomo (-) e $5 \%$ no genoma ( $\cdots)$.

Figura 3 - Valores da estatística F para análise de QTL no cromossomo 8 de suínos para as características de qualidade de carne luminosidade (L) e índice de amarelo (B).

Beeckmann et al. (2003) encontraram QTL para peso do pernil sem pele e sem capa de gordura em um IC $_{95 \%}$ de 20 a 46 cM e Milan et al. (2002) em um IC $_{95 \%}$ de 46 a $82 \mathrm{cM}$, diferentemente da região que foi encontrada neste estudo. Já para peso do lombo não foi encontrado QTL nas literaturas consultadas. Detectou-se QTL significativo a 1\% no genoma para peso da banha-rama (Figura 2; Tabela 4). A estimativa do efeito genético aditivo positivo $(0,04 \pm 0,01)$ do QTL implica que os alelos da raça Piau resultam em aumento no fenótipo e a sua variância fenotípica explica $4,1 \%$ da característica na população. Em consonância, Knott et al. (1998) encontraram QTL, em um cruzamento entre porcos selvagens europeus e Large White, para peso de banharama no mesmo cromossomo.

Detectou-se no cromossomo 8 QTL significativo a 5\% no genoma para luminosidade da carne (Figura 3; Tabela 4), porém com influência dos alelos da linhagem Comercial ( $a=-0,61 \pm 0,17$ ), e isso explica $5,21 \%$ da variação fenotípica na população $\mathrm{F}_{2}$. Foi detectado QTL para índice de amarelo, com pico em 106 cM ( IC $_{95 \%}$ de 88 a 135 cM) (Figura 3), entretanto, não foi encontrado citação sobre este QTL nas literaturas consultadas.

A atratividade da carne está relacionada com fatores como a cor (luminosidade e índice de vermelho, principalmente) e a exsudação, sendo a cor um dos primeiros atributos a ser observados pelo consumidor, tendo, portanto, grande importância na decisão desse na hora de efetuar a compra. De acordo com Barbosa et al. (2006), que analisaram esses mesmos dados fenotípicos por metodologia de componentes principais, o índice de amarelo seria uma característica redundante na avaliação dos parâmetros de qualidade de carne, podendo ser descartada das avaliações. 


\section{Conclusões}

Há locos de características quantitativas no cromossomo 5 de suínos para as características de carcaça e dos cortes de carcaça e, nos cromossomos 7 e 8, para carcaça, cortes de carcaça, órgãos internos e qualidade da carne.

É necessário o mapeamento fino para identificação dos genes responsáveis pelo efeito observado, aumentando, assim, os benefícios da Seleção Assistida por Marcadores na indústria suinícola.

\section{Referências}

ARCHIBALD, A.L.; HALEY, C.S.; BROWN, J.F. et al. The PiGMaP consortium linkage map of the pig (Sus scrofa). Mammalian Genome, v.6, p.157-175, 1995.

BAND, G.O.; GUIMARÃES, S.E.F.; LOPES, P.S. et al. Relationship between the Porcine Stress Syndrome gene and pork quality trait in F2 pigs resulting from divergent crosses. Genetics and Molecular Biology, v.28, p.88-91, 2005a.

BAND G.O.; GUIMARÃES, S.E.F.; LOPES, P.S. et al. Relationship betweem the Porcine Stress Syndrome gene and carcass and performance trait in F2 pigs resulting from divergent crosses. Genetics and Molecular Biology, v.28, p.92-96, 2005b.

BARBOSA, L.; LOPES, P.S. REGAZZI, A.J. Avaliação de características de qualidade da carne de suínos por meio de componentes principais. Revista Brasileira de Zootecnia, v.35, n.4, p.1639-1645, 2006.

BASKIN, L.C.; POMP, D. Rapid communication: mapping of the porcine Colipase gene to chromosome 7 using linkage analysis. Journal of Animal Science, v.76, p.1241-1242, 1998.

BEECKMANN, P.; MOSER, G.; BARTENSCHLAGER, H. et al. Linkage and QTL mapping for Sus scrofa chromosome 8. Journal Animal Breeding and Genetics, v.120, n.1, p.66-73, 2003.

BENEVENUTO JR., A.A. Avaliação de rendimento de carcaça e de qualidade da carne de suínos comerciais, de raça nativa e cruzados. 2001. 98f. Dissertação (Mestrado em Ciência e Tecnologia de Alimentos) - Universidade Federal de Viçosa, Viçosa, MG.

BIDANEL, J.P.; MILAN, D.; IANNUCCELLI, N. et al. Detection of quantitative trait loci for growth and fatness in pigs. Genetics Selection Evolution, v.33, p.289-309, 2001.

BOTSTEIN, D.; WHITE, R.L.; SKOLNICK, M. et al. Construction of genetic linkage map in man using restriction fragment length polymorphisms. Journal of Human Genetics, v.32, p.314-331, 1980.

CHURCHILL, G.A.; DOERGE, R.W. Empirical threshold values for quantitative trait mapping. Genetics, v.138, p.963-971, 1994.

DE KONING, D.J.; JANSS, L.L.G.; RATTINK, A.P. et al. Detection of quantitative trait loci for backfat thickness and intramuscular fat content in pigs (Sus scrofa). Genetics, v.152, p.1679-1690, 1999.

EDWARDS, D.B.; ERNST, C.W.; RANEY, N.E. et al. Quantitative trait locus mapping in an F2 Duroc $x$ Pietrain resource population: II. Carcass and meat quality traits. Journal of Animal Science, v.86, p.254-266, 2008.

FARIA, D.A.; GUIMARÃES, S.E.F.; LOPES, P.S. et al. Association between G316A growth hormone polymorphism and economic traits in pigs. Genetics and Molecular Biology, v.29, p.634-640, 2006.

GELDERMANN, H.; MÜLLER, E.; MOSER, G.; REINER, H. et al. Genome-wide linkage and QTL mapping in porcine F2 families generated from Pietrain, Meishan and Wild Boar crosses.
Journal Animal Breeding and Genetics, v.120, p.363-393, 2003.

GREEN, P.; FALLS, K.; CROOKS, S. [1990] Documentation for CRIMAP. St. Louis: Washington University School of Medicine. Disponível em: <http://linkage.rockefeller.edu/soft/crimap.>. Acesso em: 30/5/2007.

HALEY, C.S.; HILL, W.G.; BARET, P.V. et al. Detection and mapping of quantitative trait loci in farm animals. Livestock Production Science, v.52, p.135-144, 1994.

HALEY, C.; VISSCHER, P. DNA markers and genetic testing in farm animal improvement: current applications and future prospects. Edinburgh: Roslin Institute, 1998. p.28-39. (Annual Report).

KIM, J-J.; ZHAO, H.; THOMSEN, H. et al. Combined line-cross and half-sib QTL analysis of crosses between outbred lines. Genetical Research, v.85, p.235-248, 2005.

KNOTT, S.A.; MARKLUND, L.; HALEY, C.S. et al. Multiple marker mapping of quantitative trait loci in a cross between outbred wild boar and Large White pigs. Genetics, v.148, p.1069-1080, 1998.

MALEK, M.; DEKKERS, J.C.M.; LEE, H.K. et al. A molecular genome scan analysis to identify chromosomal regions influencing economic traits in the pig. I. Growth and body composition. Mammalian Genome, v.12, n.8, p.630-636, 2001.

MARKLUND, L.; JOHANSSON MOLLER, M.; HOYHEIM, B. et al. A comprehensive linkage map of the pig based on a wild pigLarge White intercross. Animal Genetics, v.27, p.255-269, 1996.

MARSHALL, T.C.; SLATE, J.; KRUUK, L.E.B. e PEMBERTON, J.M. Statistical confidence for likelihood-based paternity inference in natural populations. Molecular Ecology, v.7, p.639-655, 1998.

MILAN, D.; BIDANEL,J.P.; IANNUCCELLI, N. et al. Detection of quantitative trait loci for carcass composition traits in pigs. Genetics Selection Evolution, v.34, n.6, p.705-28, 2002.

NEZER, C.; MOREAU, L.; WAGENAAR, D. et al. Results of a whole genome scan targeting QTL for growth and carcass traits in a Pietrain x Large White intercross. Genetics Selection Evolution, v.34, p.371-387, 2002.

OTT, J. Strategies for characterization highly polymorphic markers in human gene mapping. American Journal of Human Genetics, v.51, p.283-290, 1992.

OVILO, C.; CLOP, A.; NOGUERA, J.L. et al. Quantitative trait locus mapping for meat quality traits in an Iberian $\mathrm{x}$ Landrace F2 pig population. Journal of Animal Science, v.80, p.28012808, 2002.

PASZEK, A.A.; WILKIE, P.J.; FLICKINGER, G.H. et al. Interval mapping of growth in divergent swine cross. Mammalian Genome, v.10, p.117-122, 1999.

PEIXOTO, J.O.; GUIMARÃES, S.E.F.; LOPES, P.S. et al. Associations of Leptin gene polymorphisms with production traits in pig. Journal Animal Breeding and Genetics, v.123, p.1-6, 2006.

PÉREZ-ENCISO, M.; CLOP, A.; NOGUERA, J.L. et al. A QTL on pig chromosome 4 affects fatty acid metabolism: evidence from an Iberian by Landrace intercross. Journal of Animal Science, v.78, p.2525-2531, 2000.

ROHRER, G.A. Identification of quantitative trait loci affecting birth characters and accumulation of backfat and weight in a Meishan-White composite resource population. Journal of Animal Science, v.78, n.10, p.2547-2553, 2000.

ROHRER, G.A.; KEELE, J.W. Identification of quantitative trait locos affecting carcass composition in swine: I. Fat deposition traits. Journal of Animal Science, v.76, p.2247-2254, 1998.

ROHRER, G.A.; ALEXANDER, L.J.; HU, Z. et al. A comprehensive map of the porcine genome. Genome Research, v.6, p.371-391, 1996. 
SANCHEZ, M.P.; RIQUET, J.; IANNUCCELLI, N. et al. Effects quantitative trait loci on chromosomes $1,2,4$, and 7 on growth carcass, and meat quality traits in backcross Meishan $x$ Large White pigs. Journal of Animal Science, v.84, p.526-537, 2006.

SEATON, G.; HERNANDEZ, J., GRUNCHEC, J.A. et al. GridQTL: A grid portal for QTL mapping of compute intensive datasets. In: WORLD CONGRESS ON GENETICS APPLIED TO LIVESTOCK PRODUCTION, 8., 2006, Belo Horizonte. Proceedings... Belo Horizonte, 2006 (CD-ROM).

SILVA, M.V.; LOPES, P.S.; GUIMARÃES, S.E.; TORRES, R.A. Utilização de marcadores genéticos em suínos. II. Características de desempenho e de qualidade da carne. Archivos Lationamericanos de Produccion Animal, v.11, n.1, p.11-20, 2003.

SILVA, K.M., GUIMARÃES, S.E.; LOPES, P.S. et al. Mapeamento de locos de características quantitativas para desempenho no cromossomo 4 de suínos. Revista Brasileira de Zootecnia, v.38, n.3, p.474-479, 2009.

YUE, G.; STRATIL, A.; CEPICA, S. et al. Linkage and QTL mapping for Sus scrofa chromosome 7. Journal Animal Breeding and Genetics, v.120, n.1, p.56-65, 2003.

TUISKULA-HAAVISTO, M; HONKATUKIA, M.; KONING, D.J. et al. Mapping of quantitative trait loci affecting quality and production traits eggs layers. Poultry Science, v.81, p. 919-927, 2002.

WANG, L.; YU, T.P.; TUGGLE, C.K. et al. A directed search for quantitative trait loci on chromosomes 4 and 7 in pigs. Journal of Animal Science, v.76, p.2560-2567, 1998.

WIMMERS, K.; FIEDLER, I.; HARDGE, T. et al. QTL for microstructural and biophysical muscle properties and body composition in pigs. BMC Genetics, v.7, p.15, 2006. 